\title{
ESTÁGIO SUPERVISIONADO EM LETRAS: ORIENTAÇÃO NAS MODALIDADES PRESENCIAL E A DISTÂNCIA
}

\author{
ALAN RICARDO COSTA (UNISC) ${ }^{1}$ \\ CAROLINA FERNANDES ALVES (UFSM/UFPel) ${ }^{2}$ \\ VANESSA RIBAS FIALHO (UFSM) ${ }^{3}$
}

\begin{abstract}
RESUMO: O objetivo da presente pesquisa é identificar aproximações, distanciamentos e desafios inerentes às experiências de orientação de estágio supervisionado nas modalidades presencial e a distância na perspectiva de professores de cursos de licenciatura em Letras. O escopo do estudo centra-se na perspectiva de professores que desempenham (ou já desempenharam) a função de orientadores de estágio em cursos de licenciatura em Letras Espanhol - Literaturas a distância da Universidade Federal de Santa Maria (UFSM). A justificativa para tal investigação está relacionada à notória necessidade de maior diálogo sobre os estágios supervisionados na formação docente, sobretudo na Educação a Distância (EaD). O referencial teórico da pesquisa é composto por um suporte epistemológico em sinergia com a Linguística Aplicada Indisciplinar, que se caracteriza como transgressiva, crítica e aberta à diálogos com múltiplas perspectivas, emergentes em variados campos do saber. A metodologia da pesquisa, de viés qualitativo, contou com o depoimento de quatro professores-orientadores de estágio supervisionado. Tais depoimentos, na forma de textos escritos ou vídeos e áudios gravados, foram coletados entre os meses de novembro de 2018 e janeiro de 2019, e avaliados à luz da Análise Textual Discursiva (ATD). De modo geral, os resultados da investigação indicam que: (1) orientar estágio supervisionado é algo que se aprende na prática; (2) a EaD ainda causa dúvidas, mas essas tendem a ser superadas; (3) a tecnologia é fator importante para a orientação de estágio na EaD; e (4) o orientador de estágio supervisionado é, também, um mediador de crises e conflitos.
\end{abstract}

PALAVRAS-CHAVE: Orientação de Estágio. Modalidade presencial. Modalidade a distância.

ABSTRACT: The objective of this piece of research is to identify the approaches, detachment, and challenges regarding the experiences of advising supervised internships in the classroom-based and distance formats from the perspective of professors in undergraduate courses Faculty of Arts (Letras, in Portuguese). The scope of the study is focused on the perspective of professors who play (or have already played) the role of internship advisors in undergraduate courses - Faculty of Arts Spanish Literatures on distance course from the Federal University of Santa Maria (UFSM, abbreviation in Portuguese). The justification for that investigation is related to the evident need for more dialogue about supervised internships in teacher education, especially concerning Distance Education. The theoretical background of the research is composed of epistemological support in synergy with the Indisciplinary Applied Linguistics, which is characterized as transgressive, critical and open to dialogues with multiple perspectives, emerging in varied fields of knowledge. The methodology of the research has a qualitative approach, and it also counted on the statements of four professorsadvisors of supervised internships. Such statements, in the format of written texts or recorded videos and audio messages, were collected between November 2018 and January 2019, and evaluated on the light of Discursive Textual Analysis. Overall, the results of the investigation indicate that: (1) to orientate a supervised internship is something that people learn in practice; (2) the distance education still brings doubts; however, such doubts tend to be overcome; (3) technology is an important factor for the orientation of distance education internships; and (4) the supervised internship advisor is also a crisis and conflicts mediator.

KEYWORDS: Internship Orientation. Classroom education. Distance education.

\footnotetext{
${ }^{1}$ Doutorando do Programa de Pós-Graduação em Letras (PPGL) da Universidade de Santa Cruz do Sul (UNISC). alan.dan.ricardo@gmail.com.

2 Docente da Universidade Federal de Santa Maria (UFSM). Doutoranda do Programa de Pós-Graduação em Letras (PPGL) da Universidade Federal de Pelotas (UFPel). carolespanhol@gmail.com.

${ }^{3}$ Docente da Universidade Federal de Santa Maria (UFSM). Doutora em Linguística Aplicada pela Universidade Católica de Pelotas (UCPel). vanessafialho@gmail.com. 


\section{$=$ TRAMA $=$}

\section{INTRODUÇÃO}

O estágio supervisionado é o campo de pesquisa e produção de conhecimentos teórico-práticos sobre a docência a partir de uma aproximação crítico-reflexiva das dimensões técnicas, políticas e éticas que a compõem (PIMENTA; LIMA, 2017). Além disso, o estágio supervisionado constitui-se também como o espaço formativo que articula de maneira indissociável saberes teóricos e práticos, valorizando a experiência e a reflexão na e sobre a experiência (PIMENTA; LIMA, 2017).

$\mathrm{Na}$ formação do licenciando, especificamente o licenciando em Letras, o Estágio Supervisionado é o espaço da convergência de saberes linguísticos, literários e didáticopedagógicos - construídos ao longo do curso - com a prática docente mediada pelos contextos em que ela ocorre, como, por exemplo, nas escolas de Educação Básica. É, ainda, o momento de experiências e reflexões sobre o caráter emancipatório da(s) língua(gens) a partir do seu entendimento como um fenômeno social, histórico, cultural e político.

É necessário enfatizar, porém, que o Estágio Supervisionado não é exclusivo da modalidade presencial. A Educação a Distância (EaD) também conta com espaços de Estágio Supervisionado, conforme apontado nos Referenciais de Qualidade para o Ensino Superior do MEC (BRASIL, 2007). Na condição de docentes atuantes no curso de licenciatura em Letras Espanhol - Literaturas, da Universidade Federal de Santa Maria (UFSM), em convênio com a Universidade Aberta do Brasil (UAB), buscamos refletir sobre as questões envolvendo a prática de estágio supervisionado na referida modalidade.

Dentre os variados tópicos inerentes ao Estágio Supervisionado em Letras na EaD, interessa-nos mais especificamente as questões concernentes à orientação e à formação do professor-orientador. Algumas questões mais urgentes para nós, autores da pesquisa e docentes envolvidos com as práticas de orientação de estágio, são: (1) Há particularidades para a orientação do estágio na EaD? (2) Quais os desafios do processo de orientação de estágio nos cursos de Letras a distância? (3) Como ocorre a formação de professores orientadores de estágio para atuar na EaD? (4) De que forma as experiências de orientação de estágio na modalidade presencial, ainda mais comum no meio acadêmico, influenciam a orientação na modalidade a distância?

Essas são as questões norteadoras que movem esta pesquisa, cujo objetivo é identificar aproximações, distanciamentos e desafios inerentes às experiências de orientação de estágio nas modalidades presencial e a distância, a partir da perspectiva de professores que desempenham (ou já desempenharam) função de orientadores de estágio dos cursos de Licenciatura em Letras Espanhol da UFSM-UAB. Optamos por analisar, à luz da Análise Textual Discursiva, a perspectiva de docentes que orientaram estágios primeiramente na modalidade presencial e, posteriormente, na modalidade a distância, em função de nosso próprio percurso formativo, que também seguiu tal ordem. Além disso, partimos do seguinte pressuposto: esse "caminho" (do ensino presencial à EaD), por hora, ainda é o mais usual no cenário nacional do Ensino Superior.

A justificativa para a realização desta pesquisa parte, por um lado, da demanda, no campo da Linguística Aplicada, por registros de experiências na orientação de estágio na EaD (COSTA; LIMA; FIALHO, 2019). Por outro lado, a pesquisa se justifica também pela possível contribuição que os dados colhidos e apresentados podem conferir à prática de futuros professores universitários que venham a orientar estágios na EaD. 


\section{$=$ TRAMA $=$}

\section{BASE TEÓRICA DA PESQUISA}

Contamos com alguns estudos que nos auxiliam a esboçar um construto teórico que busque responder algumas questões envolvendo a orientação de estágios supervisionados na EaD e a formação de professores orientadores do estágio em Letras nessa modalidade. Salientamos, todavia, que muitos desses estudos talvez não tenham sido pensados especificamente para a formação do orientador de estágio, ou para o ensino e a aprendizagem de línguas na $\mathrm{EaD}$, razão pela qual tentamos estabelecer cruzamentos entre as discussões teóricas e, ainda, entre os dados empíricos dos professores-orientadores que são nossos sujeitos de pesquisa.

Inicialmente, vale mencionar a contribuição de Pimenta e Lima (2017) para a mudança de perspectiva em relação ao Estágio Supervisionado nas licenciaturas. Ao defendê-lo como campo de pesquisa e produção de conhecimentos teórico-práticos sobre a docência, as autoras se opõem radicalmente à concepção que o considera exclusivamente como espaço prático dentro do currículo:

[a] prática educativa (institucional) é um traço cultural compartilhado que possui relações com o que acontece em outros âmbitos da sociedade e de suas instituições. Portanto, no estágio dos cursos de formação de professores, compete possibilitar que os futuros docentes compreendam a complexidade das práticas institucionais e das ações aí praticadas por seus profissionais como alternativa no preparo para sua inserção profissional. Isso só pode ser conseguido se o estágio for uma preocupação, um eixo de todas disciplinas do curso, e não apenas aquelas erroneamente denominadas "práticas" (PIMENTA; LIMA, 2017, p. 35)

Portanto, ao defenderem que teoria e prática são elementos indissociáveis numa formação docente crítica e socialmente situada, Pimenta e Lima (2017) rompem um certo senso comum que existe sobre o que é o estágio supervisionado, como este se articula dentro de um curso de licenciatura e, para além dele, com a escola.

Nesse mesmo caminho, serve como arcabouço teórico as discussões da Linguística Aplicada Indisciplinar (doravante LAI) - também chamada de Linguística Aplicada Transgressiva, ou Linguística Aplicada Crítica, debatida por Moita-Lopes (2006), Pennycook (2006) e Rajagopalan (2006). Grosso modo, a LAI seria uma LA "anormal", por divergir de uma LA "normal", seja esse "normal" designação para uma LA tradicional que se limita às aplicações práticas de teorias Linguísticas, seja caracterização de uma LA que enfoca tópicos meramente inerentes a métodos e abordagens de ensino de línguas estrangeiras. A LAl é entendida "como uma abordagem mutável e dinâmica para as questões da linguagem em contextos múltiplos, em vez de como um método, uma série de técnicas, ou um corpo fixo de conhecimento" (PENNYCOOK, 2006, p. 67).

Vale ressaltar principalmente a transdisciplinaridade (ou a transgressão da disciplinaridade), essencial na LAI. A esse respeito, Rajagopalan (2004, p. 410) comenta que a LAl deve ser compreendida como "um campo de investigação transdisciplinar", o que significa

atravessar (se necessário, transgredindo) fronteiras disciplinares convencionais com o fim de desenvolver uma nova agenda de pesquisa que, enquanto livremente informada por uma ampla variedade de disciplinas, teimosamente procuraria não ser subalterna a nenhuma (RAJAGOPALAN, 2004, p. 410).

Essa essência de transgressão de barreiras do pensamento disciplinar é fundamental porque, assim, a LA pode não só abordar inúmeros tópicos importantes no contexto nacional (gênero, sexualidade, discurso, relações de poder etc.) como também abarcar tais temas sob 


\section{$=$ TRAMA $=$}

a ótica de inúmeras perspectivas teórico-metodológicas (teorias transgressivas, teorias críticas, teorias do Pensamento Complexo ${ }^{4}$ etc.). No caso de tópicos ainda não abordados e sem arcabouço teórico já formulado, rompem-se as barreiras da disciplinaridade e busca-se flertar com teorias que não foram pensadas para tal tema, mas servem para ele. Tal modo de pensar e fazer a LAI ("no" e "com" o mundo em movimento) pode ser sumarizado tanto pela expressão "novos tempos, novas teorizações" quanto pela máxima "outras vozes e outros conhecimentos", ambas empregadas por Moita-Lopes (2006).

Em nosso caso, haja vista a ausência de um aprofundamento da questão da orientação de estágio supervisionado em Línguas na EaD (COSTA, LIMA; FIALHO, 2019), mostra-se pertinente buscar contribuições tanto teóricas quanto práticas/empíricas, de experiências concluídas ou ainda em andamento em diferentes áreas (como a Educação, a Pedagogia, a Sociologia etc.) e sob diversos prismas.

Dentre esses registros de experiências práticas, designadamente no caso do curso de Letras Espanhol - Literaturas EaD da UFSM-UAB, cabe mencionar a publicação "A EaD vai para a escola... E agora? O estágio curricular em cursos de formação de professores de espanhol em EaD da UFSM", de autoria de Fontana e Fialho (2012). Em tal artigo, os autores apresentam um panorama geral das principais iniciativas planejadas para os primeiros casos de estágio supervisionado em licenciatura em Espanhol na EaD da UFSM, enfocando o papel dos principais atores envolvidos (mais ou menos) diretamente na referida prática, a saber: (a) os estagiários (acadêmicos), (b) os orientadores, (c) os pesquisadores (ou professoresconteudistas) e (d) os tutores presenciais. A conclusão de Fontana e Fialho (2012) à época foi, sobretudo, a percepção de que, por mais complexa que possa ser a organização, o estágio em EaD, como todo estágio, mostrava-se - já em suas primeiras experiências - "algo plenamente factível, pese às críticas que costumam haver a esta modalidade de educação" (FONTANA; FIALHO, 2012, p. 451).

O referido trabalho seria um primeiro passo para - anos depois - a ideia da produção da obra "A EaD vai à escola: estágio presencial na licenciatura em Letras Espanhol" (FONTANA; FIALHO, 2019). Tal coletânea conta com 9 (nove) capítulos que abordam variados aspectos inerentes aos estágios supervisionados: a identidade do professor em pré-serviço, o papel do supervisor regente no estágio em EaD, entre outros.

Dentre estes capítulos, Alves (2019) problematiza algumas limitações institucionais relacionadas à gestão dos estágios supervisionados em Letras/Espanhol da UFSM, traçando um paralelo entre as modalidades presencial e EaD desde a sua perspectiva como orientadora, estabelecendo algumas reflexões que abordam a disciplina de estágio como espaço de diálogo "do qual emergem inúmeras vezes a subjetividade dos atores envolvidos" (ALVES, 2019, p. 49). A concepção de Alves (2019) vai ao encontro do que sinalizam Fontana e Fagundes (2019), que lançam um olhar sobre o processo de aprendizagem e a gradual transformação que converteu quatro professoras acostumadas à modalidade presencial em orientadoras de estágio na EaD. Observam os autores, a partir dos dados coletados, que tornar-se um bom orientador de estágio em EaD tem relação com "estar aberto, ser receptivo ao que o aluno, professor em formação inicial, tem a dizer e saber escutá-lo" (FONTANA; FAGUNDES, 2019, p. 206). É fundamental, destarte, o diálogo. Afinal, "Sem conhecer o outro, sem um olhar humano voltado ao estagiário, o orientador não conseguiria escapar da hegemonização" (idem, ibidem, p. 208).

\footnotetext{
${ }^{4}$ O Paradigma da Complexidade tem servido como suporte teórico para inúmeros estudos referentes ao curso de Letras Espanhol - Literaturas EaD da UFSM-UAB (e.g. FONTANA, 2015).

Revista Trama | Volume 16 | Número 37 | Ano 2020 | p. 47-59 | e-ISSN 1981-4674
} 


\section{$=$ TRAMA $=$}

Também vale citar o estudo do estado da arte de Costa, Lima e Fialho (2019). Sinalizam os autores que não muitas publicações tratam da formação de professores orientadores de estágio em línguas estrangeiras na EaD, motivo pelo qual docentes aprendem a ser orientadores "sendo", no sentido mais prático de "aprender a fazer fazendo", incluindo na empreitada todas as implicações da construção de uma identidade docente de orientador de estágio na $\mathrm{EaD}$, na prática e sem a teoria específica. Ademais, concluem também os autores (COSTA; LIMA; FIALHO, 2019) que é necessário o registro e a circulação - no meio acadêmico - das experiências de orientação de estágios na $\mathrm{EaD}$, para que não caiamos em um looping de constante "ausência de suporte teórico", como se fosse continuamente a primeira vez que estivesse sendo vivenciada a experiência de orientar estágios a distância.

Por conseguinte, no referido looping, o professor-orientador sempre iria aprender a fazer fazendo, pela falta de diálogo com outros colegas mediado pela publicação acadêmica. [...] O âmbito acadêmico se caracteriza, sobretudo, pelo compartilhamento de análises, experiências, pesquisas, vivências e reflexões (teóricas e práticas) sobre os mais diversos temas. A ausência de trabalhos em algum dos temas repercute no constante trabalho incerto, sozinho, individual, muito mais propenso ao insucesso do que ao êxito (COSTA; LIMA; FIALHO, 2019, p. 25).

Na perspectiva dos autores, destaca-se: embora muitos estudos importantes tenham sido desenvolvidos por meio de tentativa e erro, até a tentativa e acerto, os estudos sobre tornar-se orientador de estágio da EaD não precisam seguir esse mesmo caminho, com possíveis percalços, se registrarmos e compartilharmos mais experiências. Quanto mais "tentativa e erro" puder ser evitado pelo compartilhamento de publicação aberta na área, melhor (COSTA; LIMA; FIALHO, 2019, p. 25).

\section{METODOLOGIA}

Este estudo tem como base os pressupostos da pesquisa qualitativa em Educação (BOGDAN; BIKLEN, 1994). A ótica qualitativa foi escolhida por seu caráter mais holístico e fenomenológico, sem tantas preocupações formais com a quantificação de questões que, a nosso ver, são complexas, como aquelas inerentes à formação docente e à orientação de estágios supervisionados.

O critério para a seleção de sujeitos de pesquisa foi a experiência prévia de atuação no Ensino Superior como orientadores de estágio supervisionado na modalidade presencial, para, posteriormente, uma transição ao mesmo papel, porém na EaD. Conforme já apontado, entendemos que, até então, no Brasil, este tem sido o caminho aparentemente mais frequente: professores egressos de cursos de Letras presenciais e atuantes em cursos de licenciatura presenciais deparam-se com um mercado de trabalho cada vez mais crescente na EaD e, então, inserem-se nela e adaptam-se a ela 5 . Assim, convidamos um total de 6 professores que atuaram no curso de Letras Espanhol - Literaturas EaD da UFSM-UAB, dos quais 4 aceitaram participar da pesquisa. Eles, primeiro, tiveram experiências orientando estágios no ensino presencial e, depois, tiveram de adaptar suas práticas ao contexto educacional da EaD.

Enviamos a esses professores-participantes do estudo um e-mail explicitando nossa intenção de realizar "uma pesquisa sobre orientação de estágio na modalidade presencial e na modalidade a distância". Elucidamos, no corpo do e-mail, que:

\footnotetext{
${ }^{5}$ Estamos cientes, contudo, que essa "trajetória" em breve pode deixar de ser a mais recorrente, considerando o número cada vez maior de turmas que se formam na EaD anualmente.

Revista Trama | Volume 16 | Número 37 | Ano 2020 | p. 47-59 | e-ISSN 1981-4674
} 


\title{
$=$ TRAMA $=$
}

"Para isso, definimos como foco da pesquisa o percurso de quem primeiro orientou estagiários no ensino presencial e posteriormente começou a orientar na EaD. Essa ideia de pesquisa surgiu basicamente de algumas inquietações nossas sobre essa "transição" entre as modalidades, de maneira que gostaríamos de ampliar nossas visões e conhecer as práticas de pessoas que tenham passado por essa experiência, que é o seu caso, certo?"

Explicamos, no mesmo e-mail, a metodologia de coleta de dados:

\begin{abstract}
"Assim, convidamos que participe como sujeito de nossa pesquisa enviando um vídeo ou um áudio contando sobre sua experiência como orientador de estágio em ambas as modalidades. Pedimos que fale um pouco sobre como foram as experiências e a transição, quais foram os desafios, como foi "aprender a orientar" etc. O tamanho do áudio/vídeo é livre. Você pode comentar o quanto considerar pertinente."
\end{abstract}

O e-mail foi enviado em novembro de 2018. Recebemos as contribuições dos professores-participantes entre os meses de novembro de 2018 e janeiro de 2019. As contribuições foram enviadas por vídeo, no caso do Participante 1 (P1). As participantes 2 e 4 (P2 e P4) enviaram arquivo de áudio. A participante 3 (P3) enviou um texto escrito em arquivo digital. Para fins de preservação da identidade dos professores-participantes, quando mencionados, eles são denominados P1 (Participante 1), P2 (Participante 2) e assim por diante.

As contribuições dos professores foram avaliadas à luz da Análise Textual Discursiva (ATD), metodologia de análise criada por Moraes e Galiazzi (2007), que a definem como um

[...] exercício de produção de metatextos, a partir de um conjunto de textos. Nesse processo constroem-se estruturas de categorias que, ao serem transformadas em textos, encaminham descrições e interpretações capazes de apresentarem novos modos de compreender os fenômenos investigados (MORAES; GALIAZZI, 2007, p. 89).

Logo, a ATD é "um processo auto-organizado de construção da compreensão em que novos entendimentos emergem a partir de uma sequência recursiva de três componentes" (MORAES; GALIAZZI, 2007, p. 12). A primeira etapa da ATD, o processo de unitarização, consiste em desconstruir o(s) texto(s), fragmentando-o(s) em unidades de significado que o pesquisador considera merecer destaque de acordo com a relevância que tenham para a pesquisa. Na segunda etapa, há o cruzamento entre essas unidades de significado e seu agrupamento em novas unidades, num processo chamado categorização. Trata-se, portanto, de um processo analítico importante, posto que articula elementos antes unitários e promove o estabelecimento de conjuntos de significados, as Categorias Emergentes (CE), conferindo à pesquisa amplitude, complexidade e aprofundamento. Por fim, a terceira etapa, chamada metatexto, se refere à atividade de (re)interpretar as categorias emergentes, conectando-as, por aproximação ou afastamento, pelo exercício da escrita.

Esse percurso metodológico se deu em nossa pesquisa da seguinte maneira: primeiramente, realizamos o processo de unitarização em cada um dos materiais que recebemos (vídeo, áudio e texto em arquivo digital). Para facilitar essa etapa da análise, o vídeo e os arquivos de áudio foram transcritos. Em segundo lugar, o processo de categorização deuse a partir da comparação entre as unidades de significado destacadas em cada um dos textos, de maneira a identificar pontos de aproximação entre elas, reagrupando-as, para, assim, estabelecer as CE. Sobre esse particular, cabe destacar que, na ATD, as CE podem ser dadas aprioristicamente ou, então, serem deduzidas, como foi o caso da nossa pesquisa. A seguir, compartilhamos como resultados da pesquisa 4 (quatro) $\mathrm{CE}$, articuladas entre si através de um metatexto, terceira e última etapa da ATD. 


\section{$=$ TRAMA $=$}

\section{RESULTADOS E DISCUSSÃO}

Os resultados de nossa pesquisa mostram que é possível estabelecer muito mais pontos de aproximação do que de distanciamento entre ambas as modalidades, conforme as 4 CE que destacamos a seguir.

\section{ORIENTAR ESTÁGIO SE APRENDE NA PRÁTICA}

O tema da formação de professores formadores é considerado emergente nas pesquisas em educação (ISAIA et al., 2009; WINCH, 2009), uma vez que "[...] não se constitui, ainda, um enfoque privilegiado nas pesquisas" (ANDRÉ, 2006, p. 609). Entretanto, se existe um olhar massivo para a formação inicial de professores, fica evidente a necessidade de dar atenção para quem os está formando:

[...] a formação do professor de ensino superior carece de uma pedagogia específica [...]. Se os cursos de graduação não formam docentes para o ensino superior, mas sim para a educação infantil, ensino fundamental e ensino médio, e, ainda, se os cursos de pós-graduação estão voltados, prioritariamente, para áreas específicas de interesse de pesquisa científica, quem forma o docente para o ensino superior? (MACIEL, 2009, p. 63-64).

Investir nessa perspectiva de pesquisa exige que se reconsidere o lugar da área de ensino nos cursos de licenciatura, por mais óbvio que isso possa parecer, uma vez que essa área "é desprestigiada na carreira universitária" (PIMENTA; LIMA, 2017, p. 163), argumento endossado por Oliveira (2011) no que diz respeito aos estágios:

[...] historicamente, tanto os interesses do estágio nos cursos de licenciatura como os profissionais que se interessam por estágios em sua constituição organizacional, curricular e estrutural obtêm um baixo estatuto acadêmico (OLIVEIRA, 2011, p. 86).

Nesse olhar emergente, voltado para a área de ensino dentro dos cursos de licenciatura, com ênfase no professor formador de professores, cabe especial atenção ao orientador de estágio curricular supervisionado porque, para atuar nessa função, "não há prérequisitos, em termos de trajetória acadêmica e profissional bem como de atuação profissional [...] que vão além do Curso de Licenciatura na matéria de ensino" (WINCH, 2009, p. 14). Logo, chama atenção a frequência com que os professores enfatizam que a construção dos saberes necessários a essa tarefa ocorreu enquanto a desempenhavam (PIMENTA; LIMA, 2017; WINCH, 2009), e não ao longo de sua formação inicial, em nível de graduação e pós-graduação, aspecto que encontra respaldo no trecho de P1 a seguir:

[...] mas... assim... a MINHA experiência, a MINHA formação como orientador fol prática, né? Nunca foi na minha graduação, no meu mestrado, tampouco no meu doutorado, que foi em Educação. Nunca estudei... assim... como orientar um estágio... não... [foi] da experiência prática vivida como aluno e depois das conversas com os meus colegas [...] (P1). ${ }^{6}$

Ainda em relação à experiência como orientadores de estágio, os participantes destacam a experiência prévia na modalidade presencial. Enquanto P1 faz essa consideração no sentido de demonstrar que não vê diferenças entre orientar estágios nas duas modalidades (a não ser quanto ao letramento digital do professor, que será mencionado na CE 3), P2 e P3 destacam que essa experiência os ajudou muito como orientadores de estágio na EaD:

${ }^{6}$ Grifos nossos neste e em todos os demais trechos dos depoimentos dos participantes da pesquisa. Revista Trama | Volume 16 | Número 37 | Ano 2020 | p. 47-59 | e-ISSN 1981-4674 


\section{$=$ TRAMA $=$}

[...] eu tinha a experiência de estágio...de orientação de estágio. Então, francamente, assim... não vi diferença, não vi diferença...entre orientar estágio no presencial e orientar estágio na EaD. (P1)

[...] com certeza essa experiência, né, que eu tive no presencial, me ajudou muito depois pra orientar na EaD. (P2)

Quanto às orientações de estágio, eu já tinha uma boa experiência no ensino presencial e penso que isso me ajudou muito. (P3)

Sendo assim, são extremamente pertinentes pesquisas que deem destaque a essas experiências, visando a compreender o processo de orientação de estágio no sentido de identificar saberes que são mobilizados para isso, e se esses, de certa forma, se modificam nas modalidades mencionadas. Estudos desse tipo certamente contribuem para a reflexão sobre a ação docente do formador de professores nas disciplinas de estágio, dando condições para que ele possa entender o campo de estágio enquanto constituidor de sua identidade como orientador e, também, de sua metodologia de trabalho. Com isso, a formação que se dá na prática não será irrefletida, e poderá mobilizar elementos teóricos do campo da educação a favor da didática da área específica da formação profissional.

\section{A TECNOLOGIA É FATOR IMPORTANTE PARA A ORIENTAÇÃO DE ESTÁGIO NA EAD}

O ensino e a aprendizagem mediados por tecnologias digitais é característica ontológica da EaD contemporânea, online, em rede, de modo que os professores que atuam nela devem ter intimidade com as tecnologias ou, então, estar abertos a isso, conforme sinaliza P1 ao ponderar que, se há diferença entre a orientação de estágio de uma modalidade para outra, talvez seja o nível de letramento digital do professor orientador:

[...] me parecem processos bem próximos desde que a gente tenha...e eu acho que talvez essa seja, ãhn...a chave, né...desde que a gente como professor tenha experiência como educador a distância de maneira geral... de maneira geral tenha um pouco de intimidade com as tecnologias. (P1)

[...] eu acho que se a pessoa não tem algumas habilidades para lidar com as tecnologias, não tem uma cabeça aberta pelo menos pra se adaptar rapidamente, acho que talvez, no que tange às tecnologias, a pessoa possa ter algumas dificuldades e isso acarretar dificuldades na orientação, mas acho que fora isso, né, ao menos do meu ponto de vista particular, acho que não acontece grandes problemas. (P1)

Estamos interpretando como subjacentes aos depoimentos dos professores tanto a acepção de letramentos digitais (PAIVA, 2015), bastante popular no meio acadêmico atual, quanto a concepção vygotskyana de domínio de ferramentas. O domínio das tecnologias, nesse sentido, pode inclusive romper com as noções euclidianas-cartesianas de distância, sendo essa distância superada na EaD, conforme apontam Leffa e Freire (2013). Segundo a P4:

Para mim, a experiência de orientar na modalidade a distância foi [...] foi muito bonita, muito, muito gratificante, e que, para mim foi melhor que a que eu tenho neste momento em que sou orientadora de estágio no presencial, foi melhor no sentido que eu tinha com as alunas [da EaD] um acompanhamento diário, praticamente, e as alunas realizavam seus planos de trabalho, e tinham suas dúvidas, e sempre me mandavam elas, e sempre nos falávamos, ou via Skype, ou 


\section{$=$ TRAMA $=$}

via própria plataforma (Moodle) e tive mais contato com ela que com os próprios alunos do presencial. [...] Então eu a prefiro [modalidade EaD]. (P4)

Também no depoimento do P1 a questão da tecnologia e da superação da distância está presente.

[...] A distância não muda absolutamente nada porque a gente tem o Moodle, onde as postagens são feitas. [...] faz as orientações por Skype, esse encontro com o aluno, senta frente à frente com ele, conversa, discute os planos, faz correções, faz ampliações, sugestões...enfim...um processo natural, tranquilo, igual ao processo de orientação presencial [...]. Eu não percebo diferença. (P1)

O depoimento de P1 nos permite considerar que, apesar de ainda não ser rara certa resistência por parte de muitos professores em relação ao manejo e à inserção de tecnologias em sua prática docente, é inegável que cada vez mais a abordagem do ensino a distância tem sido integrada ao ensino presencial. Em alguns contextos universitários, a institucionalização do Moodle, que vem deixando de ser utilizado apenas como repositório de textos, para ser utilizado como recurso de mediação também na modalidade presencial, é um claro exemplo dessa aproximação. Além disso, parte da carga-horária de disciplinas ou até mesmo disciplinas inteiras ministradas a distância já é uma realidade consolidada nos cursos superiores brasileiros presenciais, conforme a Resolução CNE02/2015. Também, atualmente vemos com mais frequência abordagens baseadas no ensino híbrido (HORN; STAKER, 2015), mesclando ensino e aprendizagem online e off-line. Há, portanto, um evidente movimento de ampliação da sala de aula para além das fronteiras de tempo e espaço da modalidade presencial, incluindo também a orientação de estágio, que pode fazer uso desses recursos. Logo, é possível afirmar que os limites entre as modalidades presencial e a distância tem se apresentado mais difusos.

\section{A EAD AINDA CAUSA DÚVIDAS, MAS ELAS TENDEM A SER SUPERADAS}

As duas CE prévias - o aprender na prática e o desafio de um uso adequado de tecnologias - ajudam a entender como a EaD ainda gera dúvidas e incertezas. Da questão de "aprender a fazer fazendo", podemos destacar a falta de um suporte teórico específico para a questão das orientações de estágio em EaD (COSTA, LIMA, FIALHO, 2019). As duas CE prévias - o aprender na prática e o desafio de um uso adequado de tecnologias - ajudam a entender como a EaD ainda gera dúvidas e incertezas. Da questão de "aprender a fazer fazendo", podemos destacar a falta de um suporte teórico específico para a questão das orientações de estágio em EaD (COSTA, LIMA, FIALHO, 2019), o que envolve também dúvidas e dificuldades sobre a incorporação das tecnologias na prática pedagógica (PAIVA, 2015), conforme ilustram P3 e P1:

[...] colocar em prática uma nova modalidade de ensino foi, por muitas vezes, preocupante. Tinha dúvidas em relação a eficiência do ensino a distância, custava a acreditar que íamos formar bons professores. (P3)

[...] como é que a gente ia trabalhar estágio na educação a distância? A gente teve que pensar tudo, né? A gente nunca tinha feito. (P1)

O movimento de superação das incertezas e desconfianças quanto à orientação de estágio na EaD parece seguir o caminho da incorporação das tecnologias na educação. De acordo com Paiva (2015), após a inserção de uma tecnologia nas práticas cotidianas, vem a fase da normalização, no qual a tecnologia se integra de tal forma às práticas pedagógicas que

\footnotetext{
${ }^{7}$ A P4 enviou seus depoimentos em arquivo de áudio, em espanhol, que é sua Língua Materna. Traduzimos suas opiniões para facilitar a leitura.

Revista Trama | Volume 16 | Número 37 | Ano 2020 | p. 47-59 | e-ISSN 1981-4674
} 


\section{$=$ TRAMA $=$}

deixa de ser vista como cura milagrosa e de ser temida. Assim também acontece com a orientação na EaD, no sentido de "desmistificação" da modalidade, como podemos ver em P3:

[...] Com o passar do tempo e a seriedade com a qual encaramos o trabalho, mostrou [sic] que era possível sim, preparar muito bem os graduandos. Nessa época, eu também trabalhava em uma graduação presencial e pude comprovar que alunos da EaD, não poucas vezes, apresentavam melhor desempenho que os do presencial, mostrando que muito se deve ao perfil de aluno, da sua vontade de aprender, autonomia e capacidade de gerenciar o tempo de estudos. (P3)

Conforme o depoimento da P3, nota-se o comprometimento com a orientação de estágio na EaD um fator fundamental para a superação de dúvidas quanto a modalidade.

\section{O ORIENTADOR DE ESTÁGIO É TAMBÉM MEDIADOR DE CRISES E CONFLITOS}

Embora a perspectiva da formação do professor deva estar presente desde o começo do curso de licenciatura, em todas as disciplinas, o estágio ainda se apresenta como um divisor de águas nesse percurso formativo, sendo motivo frequente de ansiedade para os alunos, conforme demonstram os comentários de P2 e P3 a esse respeito:

Para o planejamento e a orientação das aulas, fiz um cronograma de atendimento individual por Skype [...]. Os alunos se sentiam mais seguros com a oportunidade de falar com o professor e tirar as dúvidas. [...] Nesses momentos, também procurava tranquilizá-los, para que fossem para a prática mais seguros, pois se queixavam da distância. (P3)

[...] os alunos chegavam, num primeiro momento, extremamente assustados, assim, apavorados [...] o meu trabalho eu sentia que era um pouco baixar essa ansiedade, né, e me colocar no lugar deles, mostrar que eu passei por isso também [...]. (P2)

Orientar estágio, portanto, exige do professor-orientador uma postura empática, respeitosa e dialógica. Nesse sentido, é parte de seu trabalho mediar as crises e conflitos pelos quais passam seus alunos durante o estágio, que estão relacionados não apenas com as dificuldades de mobilizar os conhecimentos específicos de suas áreas na prática pedagógica, mas também com o enorme desafio de tornar-se professor, isto é, construir sua identidade docente. Sobre tal temática, Fontana (2015) desenvolveu sua tese de doutoramento estudando a complexidade das dinâmicas do afeto e do conflito na EaD.

O estudo das interações e das afetividades estabelecidas na EaD, de modo geral, e na orientação de estágio supervisionado, de modo mais específico, pode mostrar-se promissor. Afinal, a orientação de estágio, não só a distância, mas também no ensino presencial, aparenta abarcar uma mistura de sentimentos, como medos, ansiedades, dúvidas... Orientar estágio também provoca ansiedade nos professores, conforme é apontado nos depoimentos de P2:

[...] quando eu comecei a orientar [...] despertou um pouco de medo em mim ...ao mesmo tempo que eu fiquei super motivada, eu fiquei com medo, eu digo: "ai será que eu vou fazer um trabalho legal? Será que eu vou conseguir ajudar os alunos (P2)

[...] a questão da orientação de estágio foi pra mim algo bem inovador...inovador e me assustou um pouco, eu confesso. [...] foi maravilhoso, foi muito bom! [...] Então tudo foi muito válido, sabe? E...e...e eu...eu fiquei muito feliz com o trabalho final [...] foi muito emocionante, sabe? Foi lindo. E isso de certa forma me comprovou que o meu trabalho, né, nessa disciplina tinha sido super válido, gratificante, que teve um final feliz, sabe? Eu fiquei muito, muito, muito realizada, apesar de todas as dificuldades, né, foi algo assim que pra mim foi um diferencial 


\title{
$=$ TRAMA $=$
}

na minha formação, foi um diferencial na minha vida, né...ai foi maravilhoso, assim, foi um trabalho que realmente foi muito especial, muito, muito especial, sabe? (P2)

Além disso, o processo de formar-se orientador de estágio também pode revelar incertezas, conforme já indicado na C3 e presente no depoimento de P1:

Não sei se sou um bom orientador de estágio....acho que [...] a gente conseguiu fazer bons trabalhos. Alguns resultados foram excepcionais...claro...muito mais por conta dos alunos, que se puxam mais, do que propriamente do meu trabalho $[\ldots]$.

A mediação de conflitos interpessoais pode, também, ser a chave para um trabalho mais colaborativo na EaD, por meio das tecnologias, inclusive mais que na modalidade presencial, conforme aponta a P4:

\begin{abstract}
Elas [as alunas orientandas de estágio] foram me conectando e se conectando e formando um grupo que é um grupo, um grupo muito bom nesse sentido, de que todas trabalhavam em colaboração, então tínhamos encontros diários as vezes, as vezes não tão diários, mas realmente quando tinham que entregar o plano de trabalho era diário, e depois tínhamos encontros grupais, ou seja, todo o grupo das alunas que estavam fazendo estágio comigo, e foi também uma experiência muito colaborativa, porque elas se ajudaram mutuamente durante todo o processo, trocaram muitas ideias [...] e me parece que no estágio presencial isso se perde, se trabalha mais individualmente, na distância me parece que foi mais colaborativo. (P4)
\end{abstract}

Os grupos, quando mediados pelo professor-orientador, podem reverberar em um trabalho de colaboração e compartilhamento de experiências importante para a aprendizagem coletiva, tanto no presencial quanto na EaD. Nesta última, contudo, o resultado parece ser ainda mais necessário, sobretudo para desmistificar a ideia de "distância", já destacada em linhas anteriores.

\section{CONSIDERAÇÕES FINAIS}

As primeiras experiências de estágio supervisionado em licenciatura em Letras na EaD já vêm ocorrendo nos últimos anos, sobretudo no que tange ao contexto da UAB. Assim, a situação dos orientadores de estágio supervisionado, principalmente aqueles docentes que já orientaram na modalidade presencial e passaram a atuar na $\mathrm{EaD}$, merece registro e compartilhamento na academia, razão pela qual desenvolvemos a presente pesquisa. Com o objetivo de identificar - na perspectiva de docentes de cursos de licenciatura em Letras aproximações, distanciamentos e desafios inerentes às experiências de orientação de estágio supervisionado nas modalidades a distância e presencial, elencamos uma série de questões norteadoras para este estudo, as quais resgatamos a seguir.

A primeira questão foi a seguinte: há particularidades para a orientação do estágio na modalidade a distância? Os depoimentos dos professores participantes da pesquisa nos permitem inferir que a maior particularidade parecer ser o nível de domínio da tecnologia e o letramento digital necessário para o processo de orientação. De modo geral, entretanto, não há tantas particularidades no processo de orientação em EaD, haja vista que ela pode ser enriquecida pelas experiências de orientação de estágio na modalidade presencial.

Quanto à segunda questão - a saber: quais os desafios do processo de orientação de estágio nos cursos de Letras a distância? -, cabe destacar: nos depoimentos, poucos desafios foram enfatizados. Evidentemente, a questão dos letramentos digitais e os eventuais problemas de conexão foram registrados, o que nos permite destacar a importância do domínio da tecnologia nos processos de orientação. 


\section{$=$ TRAMA $=$}

Nossa terceira questão norteadora foi: como ocorre a formação de professores orientadores de estágio em EaD? Subjacente aos depoimentos dos professores participantes da pesquisa há uma ideia de formação na prática: "aprender a fazer fazendo". Conforme já destacado em Costa, Lima e Fialho (2019), um caminho possível para fazer-se orientador de estágio é o da empiria: aprende-se a ser "sendo". Evidentemente, a teoria, quando aliada à prática, pode tornar o processo de aprender a orientar estágios supervisionados mais proveitoso e bem-sucedido.

"Como as experiências de orientação de estágio na modalidade presencial influenciam a orientação na modalidade a distância?" foi nossa quarta e última questão norteadora. Conforme já destacamos, os participantes do estudo apontam que a experiência de orientação de estágio no ensino presencial influenciou de maneira positiva, embora não especifiquem exatamente em que sentido. Nas entrelinhas dos depoimentos, contudo, nota-se a questão da experiência da gestão (ALVES, 2019).

Este trabalho, evidentemente, não esgota o tema em debate. A orientação de estágios supervisionados no ensino presencial sempre esteve na agenda do dia da educação nacional, e esse mesmo processo, agora também na $\mathrm{EaD}$, apenas amplia e complexifica o leque de tópicos a serem abordados por educadores e pesquisadores. Nossa contribuição para o debate, nesse sentido, diz respeito à questão dos procedimentos institucionais. Talvez a maior diferença - que tenha emergido dos depoimentos dos professores participantes deste estudo entre os processos de orientação nas modalidades a distância e presencial esteja relacionada aos procedimentos institucionais adotados em cada modalidade para a orientação do estágio supervisionado. Essa diferença de procedimentos talvez seja até mais notória do que possíveis diferenças oriundas da essência da orientação em si nessas modalidades, haja vista o que foi levantado nas CE: as preocupações e os desafios, que parecem ter relação com a orientação de estágio tanto na modalidade presencial quanto a distância. Entendemos que essa questão institucional interfere na experiência de orientação de estágio supervisionado de cada um, mas não na essência da função e da modalidade.

\section{REFERÊNCIAS}

ANDRÉ, M. E. D. A. de. (Org.) Formação de professores no Brasil (1990 - 1998). Brasília: MEC/Inep/Comped, 2002.

ALVES, C. F. Os estágios supervisionados nos cursos de letras/espanhol da UFSM nas modalidades presencial e a distância. In: FONTANA, M. V. L.; FIALHO, V. R. (Org.) A EaD vai à escola: estágio presencial na licenciatura em Letras Espanhol. Campinas: Pontes. 2019. p. 27-52.

BOGDAN, R. C.; BIKLEN, S. K. Investigação Qualitativa em Educação: uma introdução à teoria e aos métodos. Porto - Portugal. Porto Editora, 1994.

BRASIL. Ministério da Educação. Referenciais de qualidade para o ensino superior. Secretaria de Educação a Distância. 2007. Disponível em: <http://portal.mec.gov.br/seed/arquivos/pdf/legislacao/refead1.pdf>. Acesso em 12 de setembro de 2017.

COSTA, A. R.; LIMA, C. A.; FIALHO, V. R. Estágios Supervisionados em Línguas Estrangeiras: estado da arte e orientações para a EaD. In: FONTANA, M. V. L.; FIALHO, V. R. (Org.) A EaD vai à escola: estágio presencial na licenciatura em Letras Espanhol. Campinas: Pontes. 2019. p. 11-26.

FIALHO, V. R.; FONTANA, M. V. L. Percurso e lições: licenciatura em Espanhol a Distância UAB e REGESD. 2012. In: I Seminário Diálogos em Educação a Distância (SEDEAD). Anais... Rio Grande, Rio Grande do Sul. 2012. p. 400-412.

FONTANA, M. V. L. Complexidade e reconhecimento: as dinâmicas do afeto e do conflito na EaD. 2015. 283f. Tese (Doutorado em Educação) - Centro de Educação, Universidade Federal de Santa Maria, Rio Grande do Sul. 2015.

FONTANA, M. V. L.; FAGUNDES, A. Fazendo-se pipoca: uma reflexão sobre o amadurecimento do orientador de estágio em EaD. In: FONTANA, M. V. L.; FIALHO, V. R. (Org.) A EaD vai à escola: estágio presencial na licenciatura em Letras Espanhol. Campinas: Pontes. 2019. p. 189-208.

FONTANA, M. V. L.; FIALHO, V. R. A EaD vai para a escola... E agora? O estágio curricular em cursos de formação de professores de espanhol em EaD da UFSM. 2012. In: I Seminário Diálogos em Educação a Distância (SEDEAD). Anais... Rio Grande, Rio Grande do Sul. 2012. p. 442-452. 
HORN, M.; STAKER, H. Blended: usando a inovação disruptiva para aprimorar a educação. Porto Alegre, Penso, 2015.

ISAIA, S. M. A.; BOLZAN, D. P. V.; MACIEL, A. M. R. (Org.) Pedagogia universitária: tecendo redes sobre a educação superior. Santa Maria: Ed. Da UFSM, 2009.

LEFFA, V. J.; FREIRE, M. Educação sem distância. In: MAYRINK, M. F.; ALBUQUERQUE-COSTA, H. (Org.)

Ensino e aprendizagem de línguas em ambientes virtuais. São Paulo: Humanitas, 2013, p. 13-38.

MACIEL, A. M. R. O processo formativo do professor no ensino superior: em busca de uma ambiência (trans)formativa. In: ISAIA, S. M. A.; BOLZAN, D. P. V.; MACIEL, A. M. R. (Org.) Pedagogia universitária: tecendo redes sobre a educação superior. Santa Maria: Ed. Da UFSM, 2009, p. 63-77.

MOITA-LOPES, L. P. (Org.) Por uma Lingüística Aplicada Indisciplinar. São Paulo: Parábola Editorial, 2006. MORAES, R.; GALIAZZI, M. C. Análise Textual Discursiva. Ijuí: Ed. Unijuí, 2007. 223 p.

OLIVEIRA, R. G. Estágio Curricular Supervisionado: horas de parceria escola-universidade. Jundiaí: Pacto Editorial, 2011.

PAIVA, V. L. M. O. O uso da tecnologia no ensino de línguas estrangeiras: breve retrospectiva histórica. In: JESUS, D. M.; MACIEL, R. F. (Org.) Olhares sobre tecnologias digitais: linguagens, ensino, formação e prática docente. Coleção: Novas Perspectivas em Linguística Aplicada, Vol. 44. Campinas, SP: Pontes Editores, 2015, p.21-34.

PENNYCOOK, A. Uma Linguística Aplicada Transgressiva. In: MOITA-LOPES, L. P. (Org.) Por uma Lingüística Aplicada Indisciplinar. São Paulo: Parábola Editorial, 2006.

PIMENTA, S. G.; LIMA, M. S. L. Estágio e Docência. São Paulo: Cortez, 2017, $8^{a}$ ed.

RAJAGOPALAN, K. Repensar o papel da Linguística Aplicada. In: MOITA-LOPES, L. P. (Org.) Por uma Lingüística Aplicada Indisciplinar. São Paulo: Parábola Editorial, 2006.

TEIXEIRA, B. R.; CYRINO, M. C. C. T. Desenvolvimento da Identidade Profissional de Futuros Professores de Matemática no Âmbito da Orientação de Estágio. Bolema [online]. 2015, vol.29, n.52, pp.658-680

WINCH, P. G. Orientadores de estágio curricular: aspectos relativos à aprendizagem e à identificação com a atividade de orientação. GT08 - Formação de Professores. $32^{a}$ reunião anual da ANPED. 2009. Disponível em: <http://www.anped.org.br/sites/default/files/gt08-5765-int.pdf>. Acesso em 10. set. 2019. 